\title{
Strengthening Of Brick Walls with Openings during Construction by Steel Wire Mesh around Openings on Both Sides of Wall
}

\author{
Elsamny, M.K. ${ }^{1}$, Ezz-Eldeen, H.A. ${ }^{2}$, Elmokrany, A.A. ${ }^{3}$ \\ ${ }^{1,2}$ (Civil Department, Faculty of Engineering, Al Azhar University, Egypt) \\ 3 (Engineer in Ministry Of Water Resources and Irrigation, Egypt)
}

\begin{abstract}
A significant part of the building is made of brick wall load bearing structures. The present of openings in brick walls can have an effect on the load capacity and cracking regime after construction under working load. So, there is a need for strengthening brick walls with openings during construction. In the present study, a total of five brick wall specimens having a wall dimensions $(85 * 65) \mathrm{cm}$ and thickness $(10) \mathrm{cm}$ with square opening $(25 * 25) \mathrm{cm}$ were tested. The brick wall specimens were divided into two groups as flow.Group one consisted of one brick wall with R.C lintel $35 \mathrm{~cm}$ length as a control wall. Group two consisted of four strengthened brick wall specimens by fixed strip of steel wire mesh covered with cement mortar around opening on both sides of wall. With strip wide $(5,10,15,20 \mathrm{~cm})$. All brick wall specimens were tested under static loads in regular increments from zero up to the cracking load then failure load. In addition, wall deformations have been measured by LVDT. The obtained test results show that fixing strip of steel wire mesh covered with cement mortar around opening on both sides of wall with strip wide $5 \mathrm{~cm}$ gives an increase in the load carrying capacity up to $135 \%$ from the control ultimate capacity. However, fixing strip of steel wire mesh covered with cement mortar around opening on both sides of wall with strip wide $10 \mathrm{~cm}$ gives an increase in the load carrying capacity up to $153 \%$ from the control ultimate capacity. In addition, fixing strip of steel wire mesh covered with cement mortar around opening on both sides of wall with strip wide $15 \mathrm{~cm}$ gives an increase in the load carrying capacity up to $167 \%$ from the control ultimate capacity. However, fixing strip of steel wire mesh covered with cement mortar around opening on both sides of wall with strip wide $20 \mathrm{~cm}$ gives an increase in the load carrying capacity up to $184 \%$ from the control ultimate capacity. The results suggest that Increasing wide of wire mesh strip increases significantly the load carrying capacity of wall. However, ductility has been significantly increased. In addition, it was found that strengthening with this technique is durable, economic and easy to apply.
\end{abstract}

Keywords: Strengthening, brick walls, steel wire mesh, around openings, both sides of wall

\section{Introduction}

The most common type of masonry buildings is the brick type that is also very vulnerable. In addition, the appearance of openings in brick walls can have an effect on the load capacity and cracking regime after construction under working load as shown in fig.1, 2. Thus, strengthening these types of buildings is an essentially important task. So, the purpose of the present study is strengthening brick walls with openings during construction to increase the load carrying capacity and ductility by fixing strip of steel wire mesh covered with cement mortar around opening on both sides of wall with varying strip wide. Tumialan G., et.al. (2000) carried out an experimental study to investigate the out-of-plane strength of unreinforced masonry (URM) walls and offered a singular opportunity for performing field experimentation on URM walls strengthened with Glass, Aramid and Carbon Fiber Reinforced Polymers (GFRP, AFRP and CFRP, respectively).A mechanism of failure caused by a shear-compression effect lead to the fracture of either the upper or lower boundary masonry units. Due to this failure mode, the walls were not able to develop a higher capacity compared to the control specimen. Berkowski. P and Dmochowski .G (2001) presented examples of brick walls strengthening by two different methods. In the first method a self supporting reinforced jacket covering walls through all the building stories was used. It was also connected to new concrete floor in a cellar and new story massive floors. In the other building there was a need not only to strengthen existing walls, but also to discharge them. The problem was solved by constructing self-supported lateral steel frames that had to carry over new floors. Farooqa, S.H., et al. (2006) tested eight walls panels for compressive and shear strength evaluation. The results demonstrate that an increase in compressive and shear strength can be achieved by anchoring steel strips to the surface of masonry walls. Khan Mahmud Amanat, et al. (2007) carried out an experimental study to investigate the in-plane strength of masonry infilled reinforced concrete portal frame rehabilitated with ferrocement. The results demonstrate that the masonry infill frame repaired with ferrocement showed an improvement in performance. Elsamny, M.K., et al. (2011) presented an investigation for strengthening solid brick walls by horizontal galvanized steel mesh embedded into bed mortar between bricks during construction and investigated the effect of the number of 
horizontal steel mesh layers and the type of mortar used on walls carrying capacity. The experimental results showed that the use of this technique in strengthening solid brick walls has a great effect on walls carrying capacity depending on number of horizontal steel mesh layers and the type of mortar used. Elsamny, M.K., et.al. (2011) carried out an experimental study to investigate the strengthening of solid brick walls using vertical galvanized steel mesh fixed at one side as well as both sides of the walls with different number of layers and investigated the effect of the number of vertical steel mesh layers and the type of mortar used on walls carrying capacity. The test results clearly demonstrate the efficiency of using this technique in strengthening solid brick walls and showed that increasing number of vertical steel mesh layers gives an increase in brick walls carrying capacity. Mahmoud .B.N.A (2011) tested thirty solid brick walls strengthened by different types of steel mesh, horizontal galvanized steel mesh into bed mortar between bricks, vertical galvanized steel mesh fixed at one side as well as both sides of the walls with different number of layers and combination of horizontal and vertical steel mesh.The results demonstrate that the use of horizontal, vertical and combination of horizontal and vertical steel mesh in strengthening brick walls gives an increase in brick walls carrying capacity as well as increasing the ductility . Masne, N. S., et al. (2014) proposed a model to determine the behavior of confined masonry (CM) walls with opening under in-plane and out-of-plane loading. Elsamny, M.K., et.al. (2016) tested ten unreinforced brick walls under uniform load up to $80 \%$ of failure load till cracks occurred. Then rehabilitated with different number of steel wire mesh layers only as well as with (1,2 and 3Ø6) additional external steel bars then tested until failure. The results showed that the walls rehabilitated by a different numbers of steel wire mesh layers only gives an increase in the load carrying capacity up to $(78.79 \%)$ of the control ultimate capacity. However, added external steel bars inside steel wire mesh gives an increase in the load carrying capacity up to $(89.70 \%)$ of the control ultimate capacity. However, increasing the number of steel wire mesh layers or increasing the number of external steel bars used in rehabilitation increases the load carrying capacity of walls and increases ductility. Elsamny, M.K., Abd-Elhamed, M.K. and Elmokrany, A.A. (2017) introduced an experimental program for strengthening brick walls with opening during construction. The experimental program included testing of seven brick wall specimens divided into three groups according to the different methods of strengthening .Group one consisted of wall with R.C lintel $35 \mathrm{~cm}$ length as a control wall , group two consisted of three strengthened brick wall specimens by $3 \emptyset 8$ steel bars embedded into bed joint mortar above lintel only with lengths $(\mathrm{L}=50,65,85 \mathrm{~cm})$ and group three consisted of three strengthened brick wall specimens by $3 \varnothing 8$ steel bars embedded into bed joint mortar above lintel and sill with lengths $(L=50,65$, $85 \mathrm{~cm})$. The obtained test results show that using $3 \emptyset 8$ steel bars embedded into bed joint mortar above lintel only with length $(85 \mathrm{~cm})$ gives an increase in the load carrying capacity up to $(179 \%)$ from the control ultimate capacity. However using $3 \varnothing 8$ steel bars into bed joint mortar on lintel and sill with length $(85 \mathrm{~cm})$ gives an increase in the load carrying capacity up to $(223 \%)$ from the control ultimate capacity. Elsamny, M.K., AbdElhamed, M.K., and Elmokrany, A.A. (2017) presented an investigation for strengthening brick walls with opening during construction by using R.C. lintel and sill and investigated the effect of R.C. lintel and sill lengths on carrying capacity of brick walls with openings. The experimental program included testing of eight brick wall specimens divided into three groups according to the different methods of strengthening .Group one consisted of wall with R.C lintel length of $35 \mathrm{~cm}$ as a control wall, group two consisted of three strengthened brick wall specimens by R.C. lintel only of lengths $(\mathrm{L}=50,65,85 \mathrm{~cm})$ and group three consisted of four strengthened brick wall specimens by R.C. lintel and sill of lengths $(\mathrm{L}=35,50,65,85 \mathrm{~cm})$.The obtained test results show that using R.C lintel only with length $(85 \mathrm{~cm})$ gives an increase in the load carrying capacity up to (189\%) from the control ultimate capacity. However, using R.C. lintel and sill with length $(85 \mathrm{~cm})$ gives an increase in the load carrying capacity up to (235\%) from the control ultimate capacity. However, ductility has been significantly increased. In addition, it was found that strengthening with this technique is durable, economic and easy to apply. Elsamny, M.K., Ezz-Eldeen, H.A. and Mahmoud, M.H. (2017) "used steel plate box-section and steel angle for rehabilitated of brick walls with openings. The obtained test results show that the walls rehabilitated by using different thicknesses of steel plate box-section gives an increase in the load carrying capacity up to $46.67 \%$ of the control ultimate capacity but no significant increases in ductility. However, for walls rehabilitated by using different cross-sections of steel angle an increase in the load carrying capacity is obtained up to $66.06 \%$ of the control ultimate capacity but no significant increases in ductility. However, increasing thicknesses of steel plate box-section or increasing the cross-sections of steel angle used in rehabilitation increases the load carrying capacity of walls and no significant increases in ductility. Elsamny, M.K., et al. (2017) tested five unreinforced brick walls with opening under uniform loading. One wall was tested as control wall and was loaded until failure. Three walls were loaded up to $80 \%$ of failure load till cracks occurred and then rehabilitated using $\mathrm{L} \& \mathrm{U}$-shaped steel plate inside opening corners welded with $\mathrm{U} \& \mathrm{~L}$-shaped steel plate at both sides. Another wall was loaded up to $80 \%$ of failure load till cracks occurred and then rehabilitated using diagonal steel plate around opening at both sides. The obtained test results show that the walls rehabilitated by using different dimensions of L\&U-shaped steel plate gives an increase in the load carrying capacity up to $63.64 \%$ of the control ultimate capacity. As well as for wall rehabilitated by using 
diagonal steel plate around opening at both sides gives an increase in the load carrying capacity up to $29.70 \%$ of the control ultimate capacity. However, increasing dimensions of L\&U-shaped steel plate used in rehabilitation increases the load carrying capacity of walls. Elsamny, M.K., et al. (2017) presented an investigation for strengthening brick walls with opening during construction by using number of horizontal plies of steel wire mesh (one, two three and four plies ) embedded into bed joint mortar above lintel and under sill level. The results suggested that increasing number of horizontal plies of steel wire mesh embedded into bed joint mortar increases significantly the load carrying capacity of wall. In addition, ductility has been significantly increased.
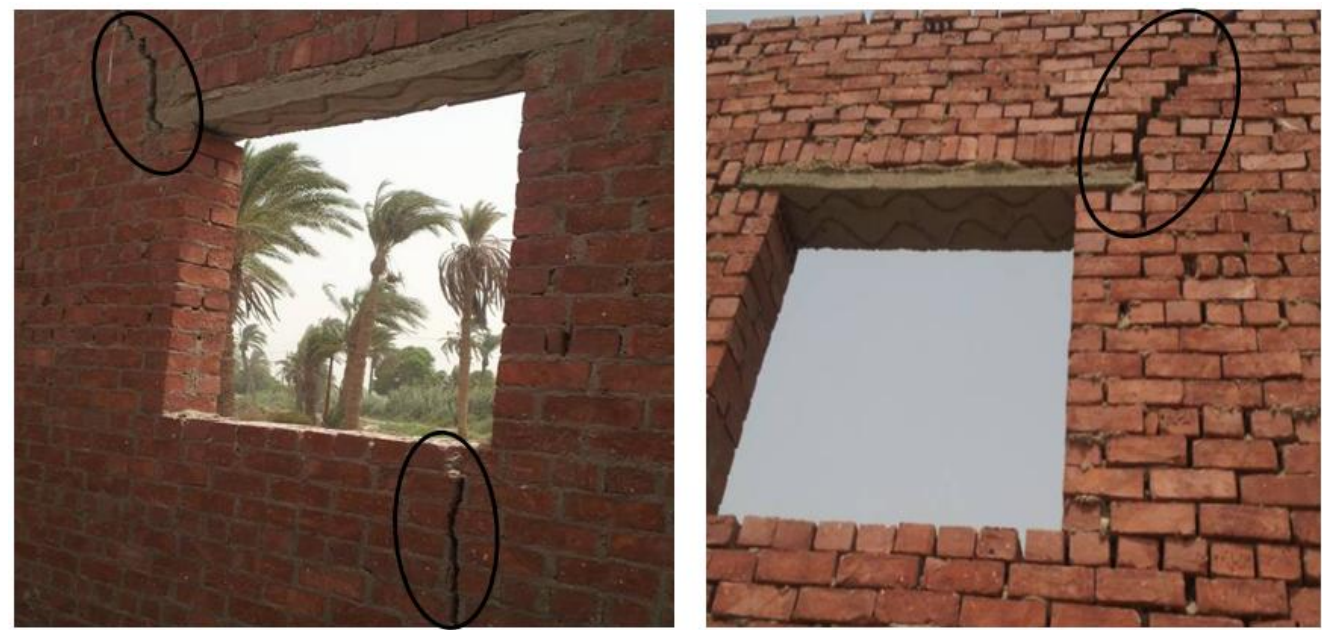

Fig- 1,2 : Cracks around window opening (Ali esa house , El.fayoum city, Egypt )

\section{Proposed Technique Of Strengthening And Experimental Program}

In the present study, two different approaches well considered for strengthening brick walls with opening during construction to prevent cracks after construction and increase the load carrying capacity of wall as well as increasing the ductility:

1. Fixing strip of steel wire mesh covered with cement mortar around opening on both sides of wall.

2. Increasing strip wide of steel wire mesh.

A total of five specimens of brick walls having a wall dimensions $(85 * 65) \mathrm{cm}$ and thickness $(10) \mathrm{cm}$ with square opening $\left(25^{*} 25\right) \mathrm{cm}$ were built. Fig. 3 shows brick wall specimens during construction. The brick walls specimens were divided into two groups according to the different methods of strengthening:

1. Group one consisted of one brick wall with R.C lintel $35 \mathrm{~cm}$ length as a control wall as shown in fig. 4.

2. Group two consisted of four strengthened brick walls specimens by fixing strip of steel wire mesh around opening on both sides of wall with strip wide $(5,10,15,20 \mathrm{~cm})$. As shown in fig.5, 6, 7 and fig.8. The strip of steel wire mesh was covered by grout of cement mortar on both sides of wall as shown in fig. 9 and then plaster the both sides of wall as shown in fig. 10 .

All specimens were tested under static loads in regular increments from zero up to the cracking load then failure load. All groups are shown in Table 1 and fig.4 to fig. 10.
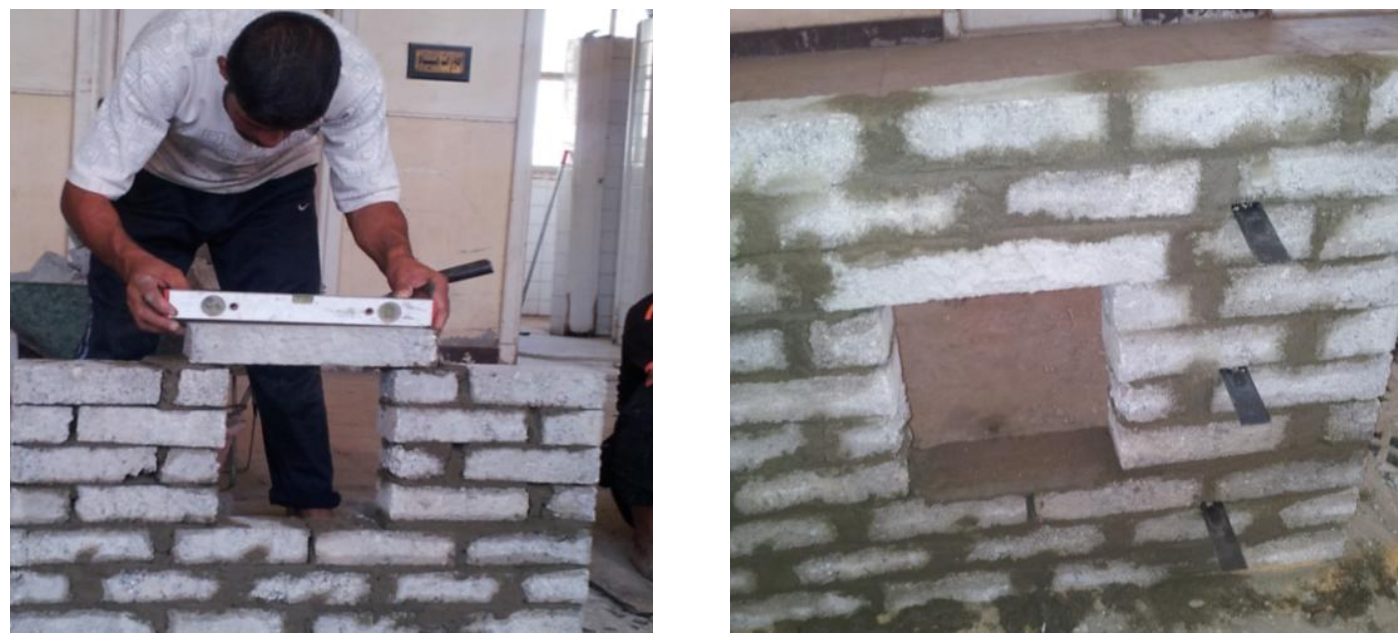

Fig- 3 Brick wall specimen during construction 


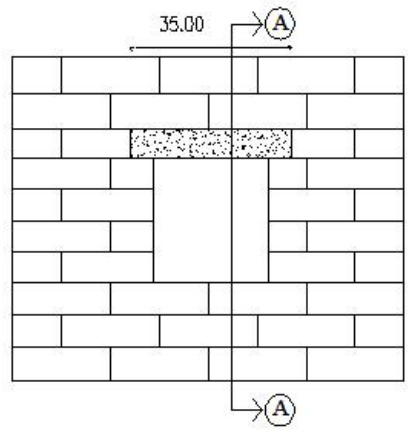

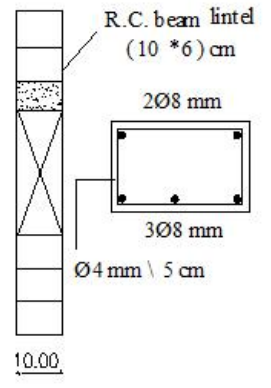

$\sec (\mathrm{A}-\mathrm{A})$

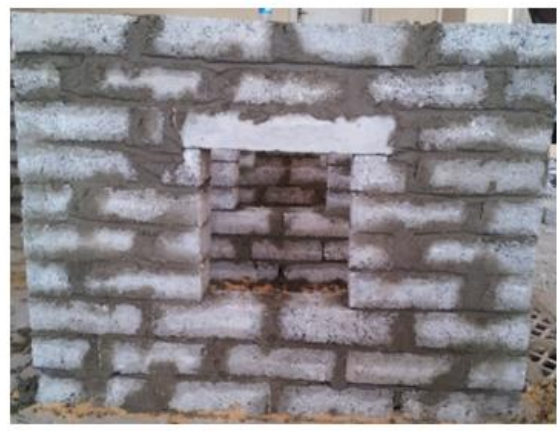

Fig- 4 Brick wall with R.C .lintel $35 \mathrm{~cm}$ (control wall)
Wide of strip $=5 \mathrm{~cm}$

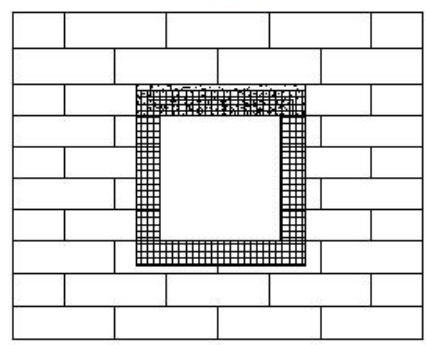

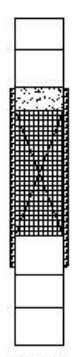

10.00
Belt of steel wire mesh with cement morter on both sides of wall

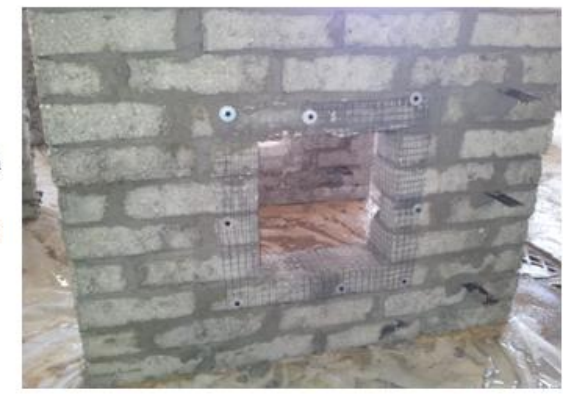

$\sec (\mathrm{A}-\mathrm{A})$

Fig- 5 Details of strengthening brick walls with opening by fixing strip of steel wire mesh around opening on both sides of wall during construction with steel wire mesh strip wide $(5 \mathrm{~cm})$

Wide of strip $=10 \mathrm{~cm}$

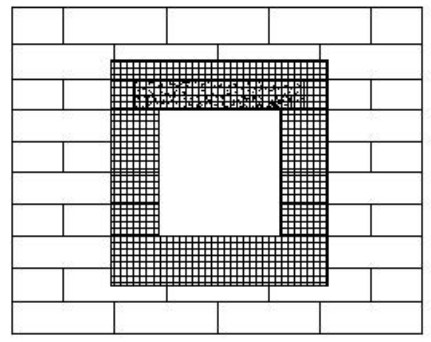

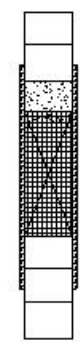

10.00
Belt of steel wiremesh with cement morter on both sides of wall

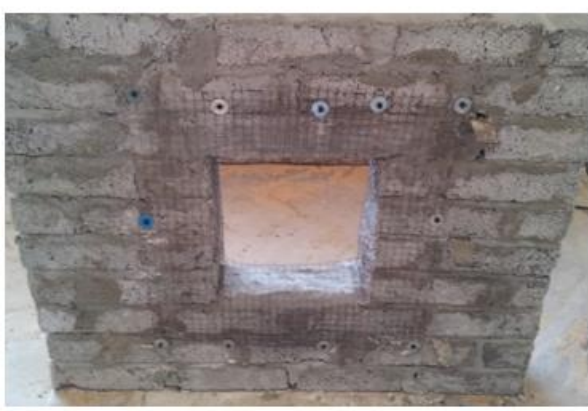

$\sec (\mathrm{A}-\mathrm{A})$

Fig- 6 Details of strengthening brick walls with opening by fixing strip of steel wire mesh around opening on both sides of wall during construction with steel wire mesh strip wide $(10 \mathrm{~cm})$

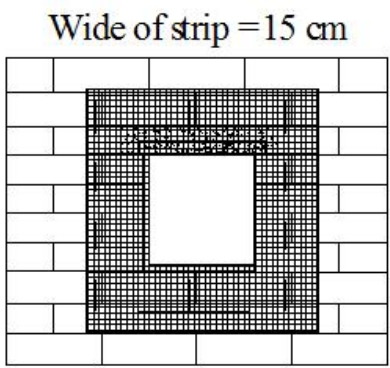

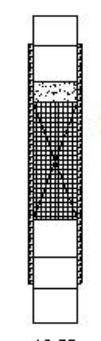

10,00

Belt of steel wire mesh with oment morter on both sides of wall

$\sec (\mathrm{A}-\mathrm{A})$



Fig- 7 Details of strengthening brick walls with opening by fixing strip of steel wire mesh around opening on both sides of wall during construction with steel wire mesh strip wide $(15 \mathrm{~cm})$ 
Wide of strip $=20 \mathrm{~cm}$

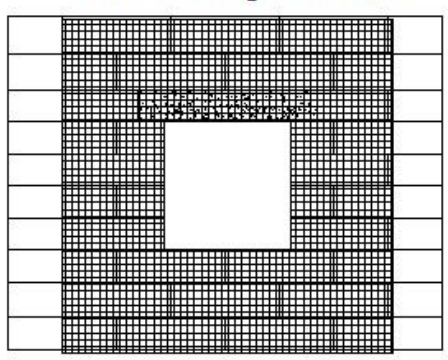

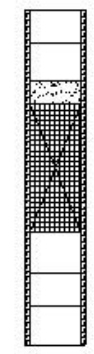

1000

Belt of steel wire mesh with cement morter on both sides of wall

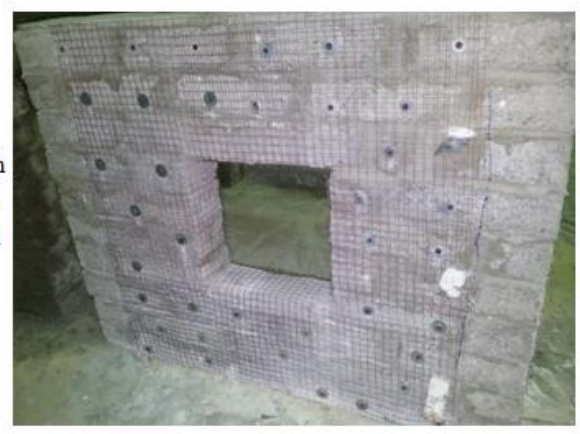

$\sec (\mathrm{A}-\mathrm{A})$

Fig- 8 Details of strengthening brick walls with opening by fixing strip of steel wire mesh around opening on both sides of wall during construction with steel wire mesh strip wide $(20 \mathrm{~cm})$

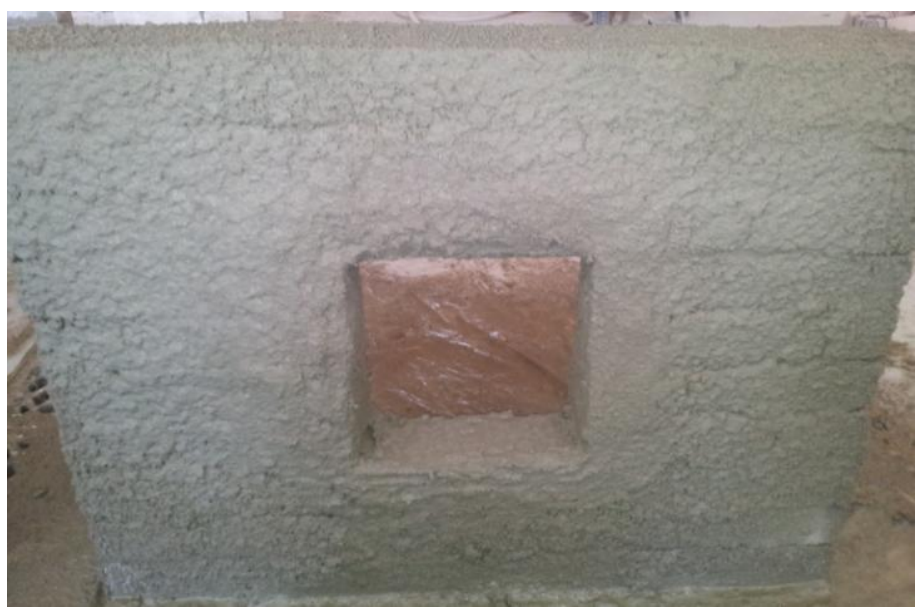

Fig- 9 Covered the strip of steel wire mesh by grout of cement mortar on both sides of wall

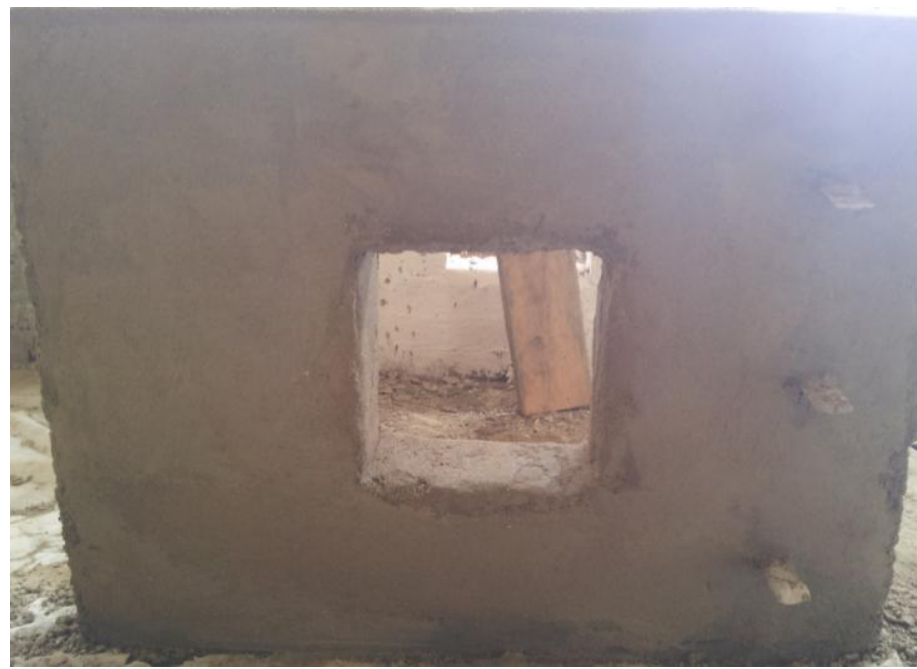

Fig- 10 Plaster both sides of wall

\section{Used Materials}

1. Solid concrete bricks with dimension $(20 * 10 * 6) \mathrm{cm}$. The average of bricks compressive strength is $(200.87 \mathrm{~kg} / \mathrm{cm} 2)$.Concrete mix consisted of crushed stone which has a maximum nominal size of $(10.0 \mathrm{~mm})$ was used as the coarse aggregate in the mix. Graded sand having sizes in the range of $(0.3 \mathrm{~mm})$ was used as the fine aggregate in the mix. Ordinary Portland cement and clean drinking fresh water were used for mixing and curing.

2. Cement mortar mix used in building the brick wall specimens was made of water-cement ratio $=0.50$ and cement sand ratio of 1:3 Natural sand passing through JIS sieve designed no. $1.2(1.19 \mathrm{~mm})$. Standard mortar cubes were taken during construction with average compressive strength $(90.82 \mathrm{~kg} / \mathrm{cm} 2)$. 
3. R.C lintel was reinforced with steel bars $5 \varnothing 8 \mathrm{~mm}$ and stirrups $\varnothing 4 \backslash 5 \mathrm{~cm}$,cross section is (10x6) $\mathrm{cm}$ with length of $35 \mathrm{~cm}$. The concrete mix consisted of crushed stone which has a maximum nominal size of $(1.0$ $\mathrm{mm})$ as the coarse aggregate in the mix, graded sand having sizes in the range of $(0.3 \mathrm{~mm})$ used as the fine aggregate in the mix. Ordinary Portland cement and clean drinking fresh water were used for mixing and curing.

4. The used steel wire mesh is galvanized steel expanded metal with weight $1.11 \mathrm{~kg} \mid \mathrm{m} 2$, sheet size $(250 * 100$ $\mathrm{cm}$ ) and fixed on the wall by nails and nuts around opening on both sides of wall with strip wide $(5,10,15,20 \mathrm{~cm})$ as shown in fig. 11,12 .

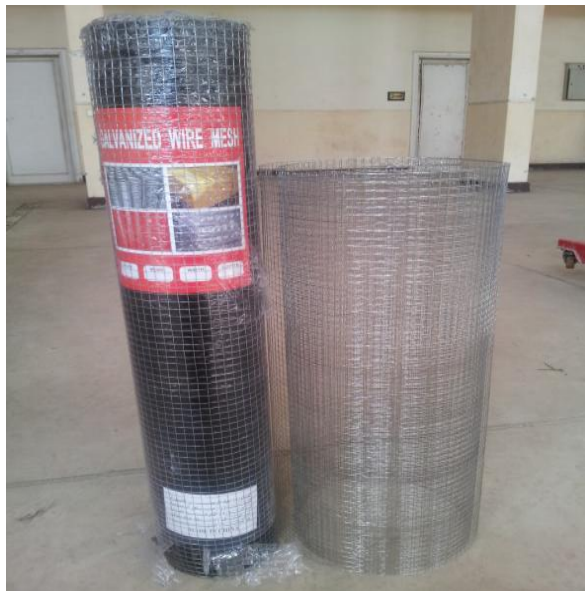

Fig- 11 Nails and nuts for fixing steel wire mesh

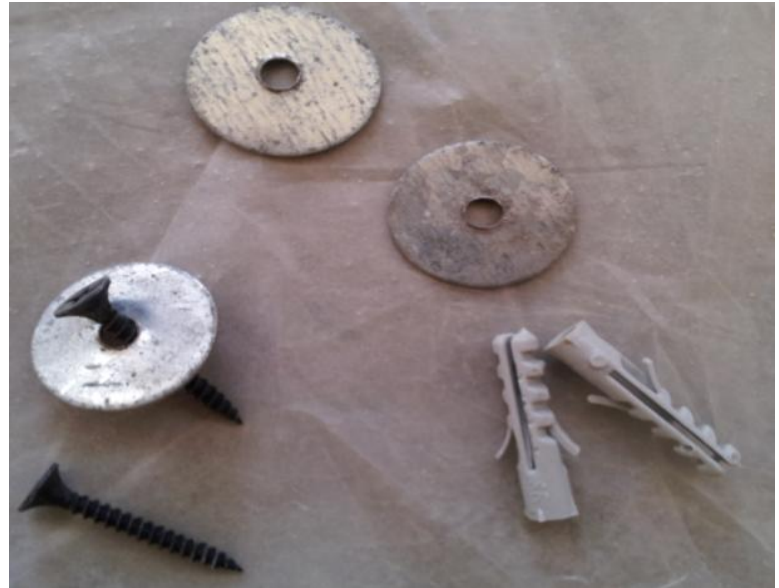

Fig- 12 Steel wire mesh on both sides of wall

\section{Test Setup And Procedure}

All wall specimens were tested under static loads using the testing machine mounted on the material laboratory of Al-Azhar University which has an ultimate compressive load capacity of 2000kN. Two u-steel beams were used for distribution the load on the wall specimens as shown in fig. 13 .Carrying the wall specimen with wood panels as shown in fig.14. Loads have been measured by the testing machine and wall deformation have been measured with LVDT under the applied loads as shown in fig. 15 . The readings of loads and wall deformation were recorded through the data acquisition system. The data acquisition system consisted of a laptop computer, a Keithley-500a data acquisition system and the lab tech notebook software package .Test setup is shown in fig. 16 .

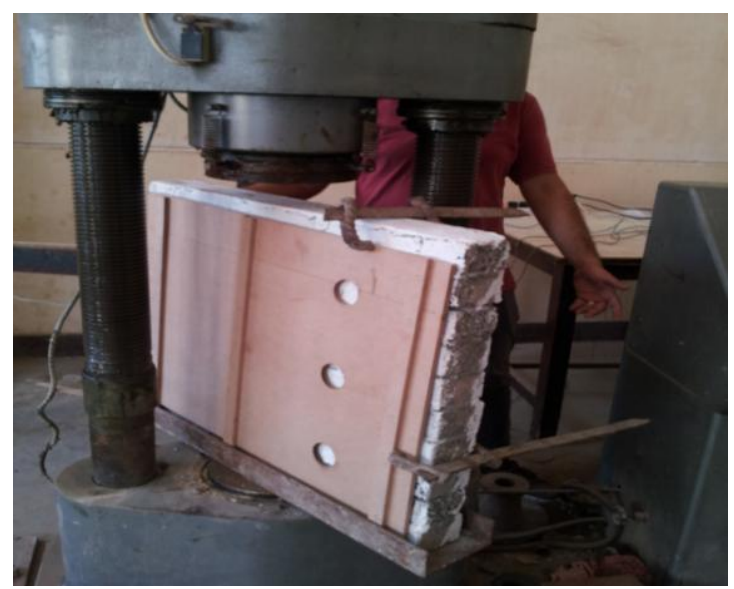

Fig- 13 Two U-steel beams for distribution load on walls

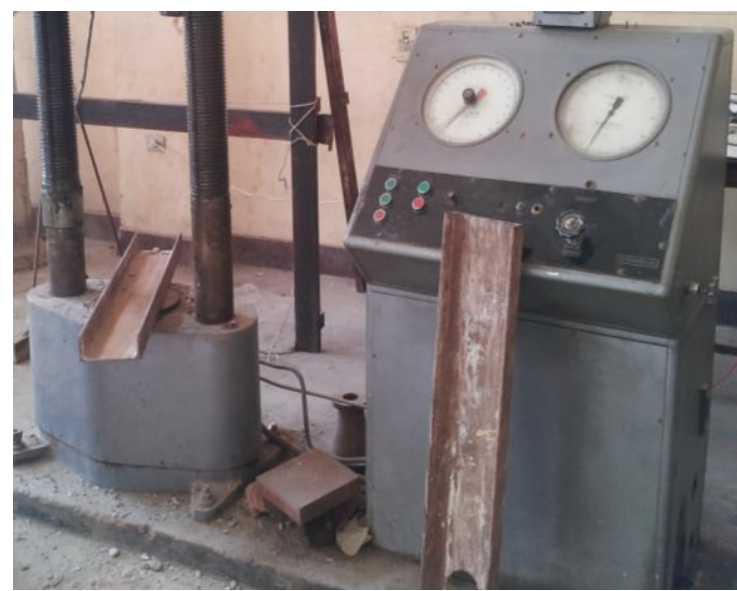

Fig- 14 Carrying wall on testing machine the by wood panels 


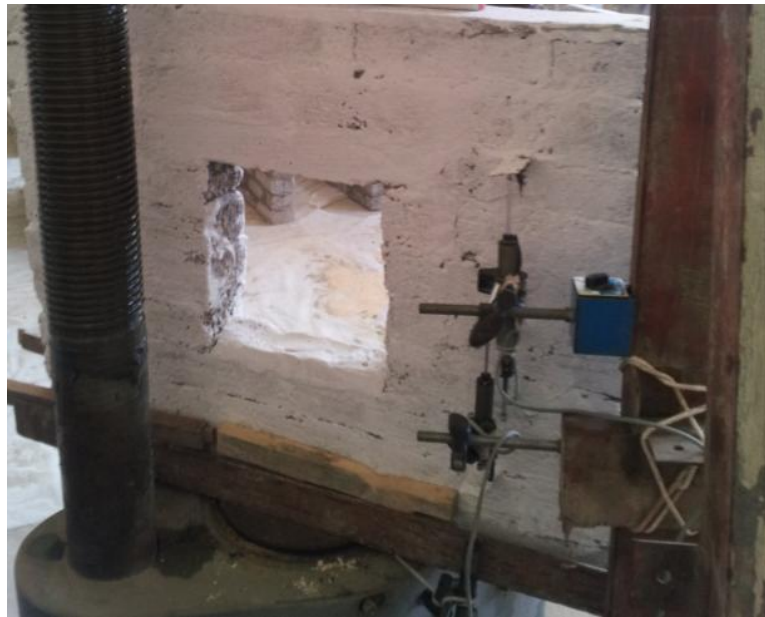

Fig- 15 Wall deformations measured with LVDT

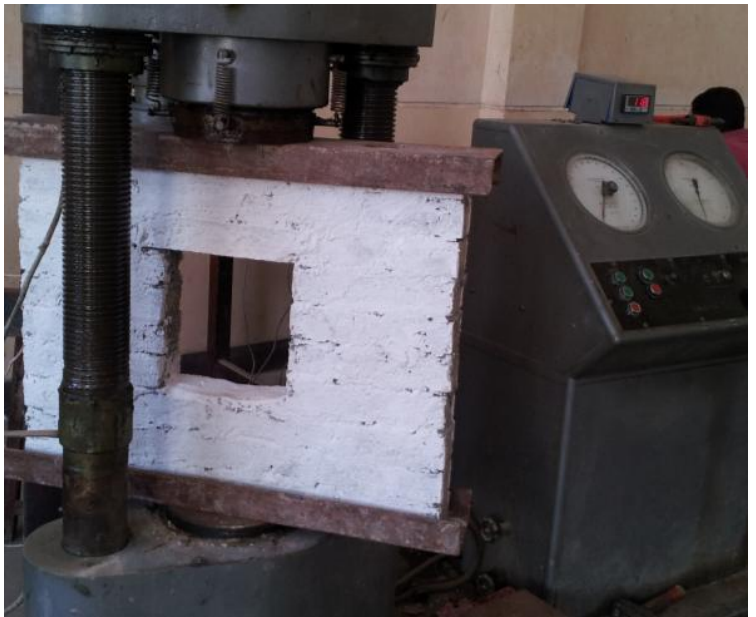

Fig- 16 Test set up

\section{Experimental Test Results}

Table 1 shows the failure loads, deformation, failure stress and strain for control and strengthened walls by different steel wire mesh strip wide of fixed by nails and nuts and covered with cement mortar around opening on both sides of wall. Fig.17 shows the relationship between stress and strain for control and strengthened walls by different strip wide of steel wire mesh fixed around opening on both sides of wall. Fig. 18 shows the relationship between ultimate stress $(\%)$ from control wall with R.C. $35 \mathrm{~cm}$ length lintel and strip wide of steel wire mesh for strengthened walls.

Table 1

\begin{tabular}{|c|c|c|c|c|c|c|}
\hline Group & $\begin{array}{c}\text { Wall } \\
\text { no. }\end{array}$ & $\begin{array}{l}\text { Strip wide of } \\
\text { steel wire mesh } \\
(\mathrm{cm})\end{array}$ & $\begin{array}{l}\text { Failure } \\
\text { Loads } \\
(\mathrm{kn})\end{array}$ & $\begin{array}{c}\text { Failure } \\
\text { Stress } \\
(\mathrm{kglcm} 2)\end{array}$ & $\begin{array}{l}\% \text { Wall } \\
\text { carrying } \\
\text { capacity } \\
\text { from } \\
\text { control }\end{array}$ & Strain \\
\hline 1 & W1 & - & 135 & 15.88 & $100 \%$ & 0.0008 \\
\hline \multirow{4}{*}{2} & W2 & 5 & 182 & 21.41 & $135 \%$ & 0.0015 \\
\hline & W3 & 10 & 207 & 24.35 & $153 \%$ & 0.0015 \\
\hline & W4 & 15 & 225 & 26.47 & $167 \%$ & 0.0019 \\
\hline & W5 & 20 & 249 & 29.29 & $184 \%$ & 0.0020 \\
\hline
\end{tabular}

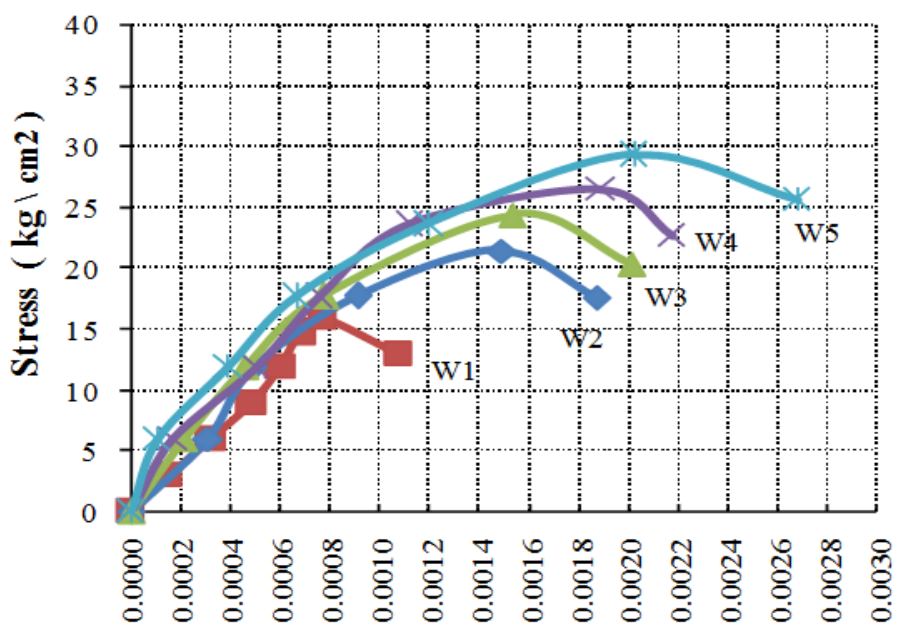

\begin{tabular}{|c|c|}
\hline $\begin{array}{c}\text { Wall } \\
\text { no. }\end{array}$ & $\begin{array}{c}\text { Strip wide of } \\
\text { Steel wire mesh } \\
(\mathrm{cm})\end{array}$ \\
\hline W1 & - \\
\hline W2 & 5 \\
\hline W3 & 10 \\
\hline W4 & 15 \\
\hline W5 & 20 \\
\hline
\end{tabular}

Vertical average strain

Fig- 17 The relationship between stress and strain for control and strengthened walls by fixing strip of steel wire mesh around opening on both sides of wall during construction with strip wide $(5,10,15$ and $20 \mathrm{~cm})$ 


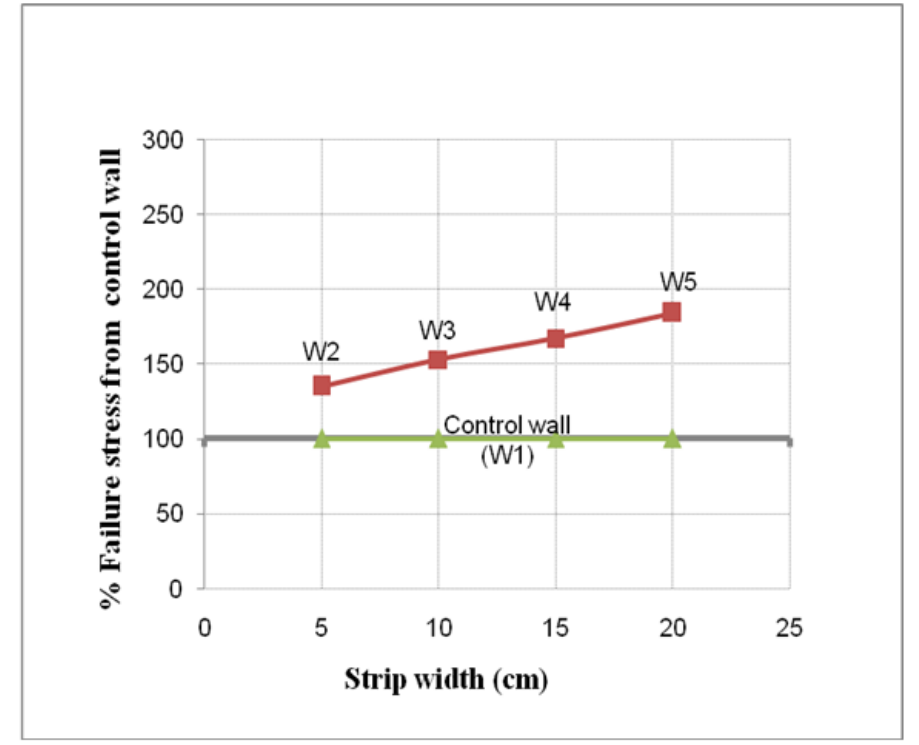

\begin{tabular}{|c|c|}
\hline $\begin{array}{c}\text { Wall } \\
\text { no. }\end{array}$ & $\begin{array}{c}\text { Strip wide of } \\
\text { Steel wire mesh } \\
(\mathrm{cm})\end{array}$ \\
\hline $\mathrm{W} 1$ & - \\
\hline W2 & 5 \\
\hline W3 & 10 \\
\hline W4 & 15 \\
\hline W5 & 20 \\
\hline
\end{tabular}

Fig- 18 The relationship between \% Failure stress from control and wide of strip for strengthened walls by fixing strip of steel wire mesh around opening on both sides of wall during construction with strip wide ( $5,10,15$ and $20 \mathrm{~cm})$

\section{Conclusions}

From the present study, the followings have been concluded:

1. Fixing strip of steel wire mesh around opening on both sides of wall during construction increases the load carrying capacity of wall.

2. Increasing strip wide of steel wire mesh around opening increases significantly the load carrying capacity of wall as well as increasing the ductility.

3. The percentage of increasing the ultimate stress for strengthened walls with fixing strip of steel wire mesh covered with cement mortar around opening on both sides of wall with strip wide $(5,10,15,20 \mathrm{~cm})$ was found to be in the range of $135 \%$ to $184 \%$.

4. Failure pattern shows that fixing strip of steel wire mesh covered with cement mortar around opening on both sides of wall during construction is more ductile.

Finally, the results suggest that strengthening brick walls with opening during construction by fixing strip of steel wire mesh covered with cement mortar around opening on both sides of wall during construction is the most efficient and economic method for increasing the load carrying capacity and ductility of the brick walls as well as preventing cracks under working load conditions.

\section{References}

[1] Berkowski. P and Dmochowski .G (2001 ) "Examples of strengthening of main walls in old buildings" Wroclaw University of Technology, Department of Civil Engineering, Building Engineering Institute, Wroclaw, Poland.

[2] Elsamny, M.K. , Abd-Elhamed, M.K. , Ezz-Eldeen,H.A.and Mahmoud, M.H. (2017) " Unreinforced Brick Walls with Openings Rehabilitated Using U \& L-Shaped Steel Plates" International Journal of Engineering Trends \& Technology (IJETT), April 2017, ISSN: 2231-5381

[3] Elsamny, M.K. , Abd-Elhamed, M.K. and Mahmoud, M.H. (2016) "Rehabilitation of Brick Walls with Openings Using Steel Wire Mesh" International Journal of Scientific \& Engineering Research, Volume 7, Issue 12, December-2016.

[4] Elsamny, M.K. , Abdelrazik, M.I. , Elsebaey, A.M. and Mahmoud .B.N.A (2011) " strengthening brick walls by horizontal galvanized steel mesh into bed mortar between bricks "civil engineering research magazine (CERM) Al - Azhar Univercity, Volume (33) , No.3, pp. 13-28

[5] Elsamny, M.K. , Ezz-Eldeen,H.A.and Mahmoud, M.H. (2017) "Structural Behavior of Brick Walls with Openings Rehabilitated With Steel Plates Box-Section and Steel Angles " International Journal of Scientific \& Engineering Research (IJSER), Volume 8, Issue 4, April-2017.

[6] Elsamny, M.K. ,Abd-Elhamed, M.K. , and Elmokrany, A.A. (2017)" Experimental study of brick walls with opening strengthened during construction by using steel bars embedded into bed joint mortar above lintel and sill " International Journal of Engineering Research \& Technology (IJERT) volume.6 -issue.01-january-2017

[7] Elsamny, M.K. ,Abd-Elhamed, M.K. , and Elmokrany, A.A. (2017)" Effect of R.C. lintel and sill lengths on carrying capacity of brick walls with openings " International Journal of Engineering Technology and Management (IJETM) Volume.4 -Issue.02-April2017.

[8] Elsamny, M.K. , Ezz-Eldeen,H.A.and Elmokrany, A.A (2017) " Experimental study of brick walls with opening strengthened during construction by using steel wire mesh embedded into bed joint mortar between bricks" International Journal of Engineering Science Invention (IJESI) Volume 6, Issue 5, pp. 15-24, May-2017. 
[9] Elsamny, M.K., Abdelrazik, M.I. , Elsebaey, A.M. and Mahmoud .B.N.A (2011) " strengthening brick walls using vertical galvanized steel mesh fixed at both sides of the walls " civil engineering research magazine (CERM) Al - Azhar Univercity, Volume (33), No.3, pp. 29-47

[10] Elsamny, M.K., Abdelrazik, M.I. , Elsebaey, A.M. and Mahmoud .B.N.A (2011) " strengthening brick walls using vertical galvanized steel mesh fixed at both sides of the walls " civil engineering research magazine (CERM) Al - Azhar Univercity, Volume (33), No.3, pp. 29-47.

[11] Farooq S.H., Ilyas M. and Ghaffar A. (2006) "Technique for strengthening of masonry wall panels using steel strips" ASIAN Journal of civil engineering (building and housing) vol. 7, no. 6 (2006) pages 621-638.

[12] Khan Mahmud Amanat, Maksudul Alam , M. M. and Shahria Alam , M. (2007) " Experimental investigation of the use of ferrocement laminates for repairing masonry in filled RC frames" journal of civil engineering (IEB), 35 (2) (2007) 71-80.

[13] Mahmoud .B.N.A (2011) " strengthening of brick walls and cost study analysis " Ph.D. Thesis , Al-Azhar University, Cairo, Egypt.

[14] Masne, N. S and Watile , R.K. (2014) "In-plane and out-of-plane behavior of confined masonry wall with opening". international journal of innovative research \& development March, 2014 Vol. 3 Issue 3.

[15] Tumialan G., Myers, J.J. and Nanni A. (2000) "Field evaluation of unreinforced masonry walls strengthened with FRP composites subjected to out of plane loading," ASCE Structures Congress 2000, Philadelphia, PA, M.Elgaaly, Ed., May 8-10, CD version, \#40492-046-004, 8 pp .U.S. National Science Foundation Wroclaw University of Technology, Department of Civil Engineering, Building Engineering Institute, Wroclaw, Poland 